\title{
Culture of National Philosophical Communities: the Project Dedicated to the Research of Modern Ukrainian Philosophical Traditions
}

\author{
Lidiya Bogataya \\ Doctor of Philosophical Sciences, \\ Professor at Cultural Studies Sub department \\ in the Odessa National I. I. Mechnikov University \\ (Odessa, Ukraine) \\ E-mail: 1.bogataya@ukr.net \\ ORCID: 0000-0002-1250-8608
}

The article introduces a new Ukrainian research project related to the preparation of a collective monograph. This monograph will highlight the activities of modern Ukrainian philosophical communities. Such communities in their totality constitute a modern national philosophical culture and its study belongs to the category of macro-humanitarian research.

The basis for a holistic observation of a culture is, on the one hand, digital technologies that enable technically to take into account practically all the studies that are carried out in a particular field in a certain period of time. On the other hand, new methodological developments are emerging that allow us to quickly process large text arrays. An example of such methodological innovations can be considered the study of American-Italian literary critic Franco Moretti. Moretti examines the opportunities that arise when using "distant reading."

The article emphasizes that the main advantage of "distant reading" is the possibility of taking into account the whole body of texts, and not only its canonical kernel.

Introduces the idea of "compression reading" as a special kind of "rapid reading", which allows you to get the most general idea of the text based on the analysis of the title of the text and its annotation. The development of compression reading technologies along with distant reading technologies will allow efficient and efficient processing of large array of texts.

The expediency of actualization of the whole textual array formed in this or that humanitarian field of research is associated with the development of a new ethic. This ethic is the ethic of collective labor. A new understanding of the collective is considered, which is possible only with careful consideration of any manifestation of the individual.

Keywords: macro-humanitarian studies, arrays of texts, philosophical culture, philosophical tradition, Ukrainian philosophical culture, compressed reading, distant reading

Received January 30, 2018; accepted March 3, 2018

Future Human Image, Volume 9, 2018:

DOI: $10.29202 / \mathrm{fhi} / 9 / 2$

(C) Bogataya, Lidiya, 2018 


\section{Introduction}

An attempt to view a particular national philosophical culture in its entirety and complexity up to the very last time seemed a task almost impracticable and unnecessary. Indeed, what can the new philosophers give to the global humanity who builds its arguments on the "edge of the philosophical mainstream", far from the world's philosophical trends, often with very strange and unusual methods? However, in recent years, researchers have arrived at the conclusion that modernity requires the consideration of every "shift in thought", for all of them collectively characterize all the planetary mental processes. For example, the American-Italian literary critic Franco Moretti proposes to re-examine the influence of key European literary traditions on the development of literature around the world [Moretti, 2016].

Digital technologies and challenges of the "new ethics" (the ethics of a new man) stimulate the development of humanitarian macro-research, to which a Ukrainian project of studying contemporary Ukrainian philosophical traditions belongs.

\section{Technical and methodological prerequisites of the project}

The results of philosophical work settle in a multitude of texts: articles and monographs. Articles are published in journals of very different levels. Some of these publications are recognized in the national professional community and are included into the international science-metric databases. Others are known only in the narrow circle of those individuals who directly cooperate with them. And, nevertheless, the existence of such publications is justified, because with these publications many young researchers start their path to real science, to philosophy. Such journals are more tolerant towards various formal authorial innovations, and this fact stimulates the development of the entire research culture. However, unfortunately, many of the noted journals are practically "not visible": neither within the national professional community, nor, especially, in the global world. Therefore, numerous texts settle "dead weight". It is difficult to calculate how many such publications annually are out of experts' sight.

Not the best fate awaits those texts that are published in the journals of a higher level. The reason is that they are also not read much. Alas, but "misunderstanding" seems to have become a characteristic feature of our time. The dependence turns out to be inversely proportional: the more people start to write, the less they read. In addition, in this situation it seems clear that it's time to talk about new techniques of reading. Such techniques could be called, for example, "fast", "compressed", or "concise" reading.

A variant of the new reading technology is offered by the already mentioned Franco Moretti, who has called this reading "distant reading."

Moretti actively promotes the introduction of digital methods into the human studies ("digital humanities" (DH)). Due to the possibilities of digital humanities, the problem of accounting for everything that had been already published within a particular topic in a certain period of time is easily solved. However, here the researchers confront with the problem of the analysis of the formed body of texts, that is to say more precisely, the problem of macroanalysis of the textual array. For the last twenty years, Franco Moretti has been trying to develop a similar line of research within the literary criticism. In this case, the texts are read not so much "in the depths" ("close reading"), as examined against the background of the whole text array.

Moretti's innovations are interesting at least for two reasons. Firstly, thanks to the methods used by him, practically all the texts that were written down (for example, for one or another discipline at one time or another) can be taken into consideration. Moretti, while studying 
British literature, notes the existence of some recognized "canon" in the whole body of texts which comprises approximately one percent of all the written. These texts Moretti calls "texts of the canon" [Moretti, 2016: 250], and all the rest texts he labels as "The Archive of the Great Unread" [Moretti, 2016: 249]. While reading those texts which were included into this archive, the researcher notes that "the usual coordinates are lost — only a lot of hybrids and oddities are visible, in relation to which the categories of literary taxonomy are useless" [Moretti, 2016: 249]. These texts can be called abnormal, unusual, and most often they do not fall into the field of researchers' view because of their otherness, and marginality.

If we move from literature to any other humanitarian field of research, the results will most likely be the similar: there are texts that canonize this or that research, and practically unknown marginal text arrays.

The second reason why Moretti's studies are viewed as very promising lies in the following. If "distant reading" is aimed at mastering not just one text but a whole text corpus, then it becomes possible to view this case as some kind of integrity and observe the various processes, which are characteristic for this particular integrity.

Thus, the technologies of macro-humanitarian analysis are actualized. It is clear that scientists need to create all these technologies as well as to develop ways for digital visualization of these or those subjects. There many other tasks arrive. Moretti's works are still the first pioneer researches in the corresponding direction.

In numerous discussions of contemporary literary critics on Moretti's innovations, we can often hear the question: why do we need all these macro-studies, macro-visualizations at all? What can they give to a particular person? And this question seems rather strange for modern scholars involved, for example, in the research on the dynamics of complex systems, complexity as such. For them, the main result of the efforts spent on the analysis of textual arrays is seen in the emerging possibility of some "taming of complexity", mastering of infinite plurality as well as understanding the trends characteristic of modern humanities in general.

Compressed reading. Intellectual consideration of large text arrays actualizes the need for the development of special reading techniques, of which we have already spoken above, that is, "compact", "compressed", "fast", "concise" reading.

We can try to show the difference between "compressed reading" (this term will be used later) and "distant reading."

Compressed reading assumes the mastering of the text not in the fullness of its meaningful revelations but only in the most important direction of development of thought singled out and emphasized by the author of the text, which is fixed in: 1) the title; 2) text annotations. Compressed reading is to some extent a formal reading that allows a researcher to discover the relationship between these or those certain form-determining text units.

The technique of compressed reading can be based, at least, on two historical traditions. First, we are talking about the tradition of studying the "title phenomenon". In this direction, one can pay attention to the existing Russian "school" of title research, which originates from Sisigmund Krzhizhanovsky's work "Poetics of Titles" [Krzhizhanovsky, 1931] and now is being developed, for example, by researchers grouped around the conference "The Title Phenomenon". This conference has been held for almost twenty years by the Russian State Humanitarian University. Moretti also gives considerable attention to the study of the title. For example, he writes: "The title becomes the place where the novel as language meets the novel as a product of consumption" [Moretti, 2016: 251]; or "it is interesting to identify clusters within a group of names, title styles" [Moretti, 2016: 269]. The works of F. Moretti 
and all those scholars who are involved into this field of research constitute one of the modern traditions of studying the title.

As for the analysis of annotations, we can also point to the formation of a new research approach called SFTs (small sized texts, mini texts, short texts) (study of small text forms) (see, for example, a small paper on this subject [Dzykovych \& Langer, 2017]).

"Compressed reading" implies the development of a methodology that allows to relate effectively not only the "title" and the "annotation", but also the entire "title complex", through which a kind of notional (semantic) compression is carried out.

"Compressed reading" should not be confused with the "distant reading" which is aimed at solving absolutely other problems. "distant reading" is aimed at simultaneous updating of a large bulk of texts as well as revealing ways to visualize them.

As for the "compressed reading", it is aimed at a single text, the way it is read quickly, in some sense at "rough mastering".

"Compressed" and "long distant" reading don't diminish the traditionally accepted practices of working with texts, which in different humanitarian traditions can be named differently: "close reading", "hermeneutic tradition of working with text", "technique of deconstruction". Each of these types of reading is aimed at solving various problems. None of the abovementioned types of reading is better or worse than another one. It is just different.

Can all these processes interest philosophers? I dare to assume that "yes, they can" because philosophy in its original focuses on the comprehension of the Whole. Thanks to the power of modern computers, for example, it is possible to track macro-epidemiological processes. The complexity and ambition of this task requires the application of joint efforts of philosophers, literary scholars, mathematicians, historians, linguists etc.

\section{Ethical challenges of the new era}

A new world, the transition into which many people now feel, already reveals its distinctive features. One of these features I want to call "collectiveness". Unfortunately, this Russian word is difficult to translate in all its semantic completeness into other languages. Any translation will be incomplete. For example, in Russian this term correlates with the word "conciliarity" which has deep orthodox roots. The famous Russian philosopher Vladimir Solovyov devoted his philosophical considerations to "conciliarity" [Soloviev, 1990]. Today, taking into account the challenges of the early $21^{\text {st }}$ century, it seems that it is the experience of the conciliarity, a special kind of collectiveness that the Orthodox world can convey to the global humanity as a hard-won, gained value.

Collectiveness in the deepest sense of the word is a special human unity in which, on the one hand, every person is heard, and on the other - there is a union of individuals into a single wise Whole. Perhaps, it was this Whole that Stanislav Lem had foreseen and called it Ocean Solaris.

The wisdom of the Whole is that it does not suppress unique human individuality, but is tuned to the harmonious co-organization of billions of sentient beings into a "holistic oceanic sound". Cultures in which this trend will be felt to some extent, probably, will be able to use more effectively the opportunities of the new time.

In his time, a very interesting Russian thinker, Nikolai Fedorov, proposed an unusual idea to the world, "the resurrection of the dead". This thought seems profoundly utopian only at first glance. Modern reality shows that the "resurrection from the dead" has actually 
begun. This kind of "resurrection" can be applied to the digitization of numerous texts lying for decades unread in various archives, "archives of the great unread". Thanks to modern digital technologies, these texts acquire the possibility of an almost instantaneous "revival". In addition, we can talk about this as a kind of "resurrection from the dead". Thus, national and universal culture acquires its lost completeness.

Thus, the dictatorship of time is softened and the despair of some authors who fear that they may not be heard today, decreases, because such an opportunity may be provided tomorrow.

The mastery of the new Whole carries in itself and many other perspectives that will be revealed to the person who has embarked on the path of comprehending the collective experience.

The mastery of a complex whole, the understanding of the Other, unexpectedly updates the topic of "caring for oneself".

For many centuries, the ethics and practice of "taking care of oneself" ripened in the depths of philosophy. It is possible to enumerate the names of philosophers who spoke about this directly or indirectly. However, in this text I want to draw attention to the two main thoughts of one of the founders of French existentialism, Gabriel Marcel.

Marcel wrote: "Only insofar as I assert myself as not being someone in particular, I can ... recognize the existence of someone else" [Marcel, 2003:150]. Unfortunately, in the modern world people seem to be forced to do the opposite. All are covered by the search of one or another identity, revealing a plan for being someone in particular. Discovering his next identity, a person moves away from himself, from the deep self, from a unique "inner melody". Marcel speculates on this melody, stating that it is an attentive listening to this melody that gives the person experience to recognize the Other. Only a person who is accustomed to listen to himself in the practice of "taking care of oneself" can hear and distinguish the Other.

Failures, in fact, the "fiasco" of the collectivization experiments that took place at the early Soviet era (20-30-ies of the $20^{\text {th }}$ century Soviet Russia), are precisely related to the fact that the government tried to "force collectivize" those people in whom it wanted to exterminate the individual principles.

While real collectiveness is possible only on condition of a trembling, patient, calm nurturing of the individual, it is "different". Moreover, in this sense, "distant reading" techniques proposed by Moretti, are seen as a manifestation of a new collective ethics.

In this connection, another idea of Gabriel Marcel is interesting: "a man who has lost even a vague consciousness of the violence committed over him, is no longer a man in the full sense of the word" [Marcel, 2003:158]. Of course, it is dangerous and difficult to analyze this thought, torn from the general context of the philosopher's speculations, and yet, even taken out from the context, it seems very important.

Awareness of the violence perpetrated against a man makes everyone even more a man. The lessons of "forced collectivization" that survived not only the peoples of the "Soviet world", contributed much to the strengthening of the individual which is so necessary for joining the new collective.

Any real philosophy begins with finding your own melody, setting up your unique voice, which not only does not try to suppress the voices of others, but on the contrary, tries to organize harmonious consonance with them.

History shows that there cannot be a single right philosophical system, for all these systems exist in complementarity, mutual opening. It is for this reason, as paradoxical as it may seem, that it is the easiest way for real philosophers to accept the newly understood collective. A 
philosopher feels in the most acute way the violence perpetrated on man, because he listens to his own source with intense and continuous attention.

Of course, scientists might object: while philosophers are just going to learn their collectiveness, scientists of various specialties are actively implementing a variety of interdisciplinary projects. This objection can be answered by the fact that interdisciplinary practices are inseparable from the universal culture, which reveals itself, including the Philosophical culture. However, this is a topic for a separate discussion.

\section{New Ukrainian project}

In the light of all that has been said, there is no need to specifically argue the relevance of the project to create a collective monograph "Modern Ukrainian Philosophical Traditions." This is the supposed collective work of Ukrainian philosophers who follow the history of their own "philosophical way" and try to understand the intellectual role of philosophical communities in the formation of Ukrainian national culture, the culture of Ukrainian philosophical discourse, in educating those who aspire to go along the Path of Philosophy.

For any local culture, the emergence of a philosophical tradition plays a special role. On one hand, thanks to philosophy, the best that has been gained by world philosophical thought is brought into the national soil. On the other hand, in specific local cultures, some "unique", "private", absolutely inconspicuous and insignificant "local" philosophical deviations are always formed. Often, these deviations are not taken into account, are not considered; they are classified as a category of marginal manifestations. The fate of such response-deviations has already been described above. The participants of the intellectual process themselves say that their texts are buried in "mass graves". Although every text is worth life, fate, thought. Many of these thoughts could and are intended to become infinitely fruitful for the development of a particular culture.

Describing the very idea of creating a collective monograph, it is necessary to focus on several of the most important goals for this project.

1. Formation of conditions for subsequent reflections of the history of modern Ukrainian philosophical discourse.

2. Attracting attention to the activities of philosophical communities as some peculiar nurseries of philosophical thought.

3. Creation of a collective monograph as an academic product of a special kind, suggesting readiness for joint intellectual actions that contribute to understanding the position of the Other.

4. Popularization of philosophical ideas, attracting a wide range of readers to the philosophy.

The monograph can become the beginning of the next phase for the project associated with a more detailed digitization of the actualized text bulks.

In the articles included into this monograph, the authors will focus their attention on the following very important moments: the characteristics of the causes and conditions that stimulated the emergence of a community; the figure of the "leader" around whom a group of followers was formed; detailed references to the most significant research results; information on published articles, monographs, and much more.

In the writing of this monograph, the researchers should take into account the experience of the American sociologist Randall Collins, who had prepared a fundamental and extremely 
interesting for many reasons work "Sociology of Philosophies: The Global Theory of Intellectual Change" [Collins, 2002].

Modern political scholars are discussing the question of how many of the most important poles will be in the world in which we are all entering now - one, two, three or more? From philosophical point of view, I want to offer a different answer. The new world is a multidimensional world in which none of the dimensions is dominant. An exclusively economic or political dimension of the world will soon become a manifestation of the out-of-date onedimensionality that strangles humanity. A multidimensional world presupposes the development of multidimensional thinking skills (see the monograph "Multidimensional Thinking" on this subject) and specific multidimensional practices. It is these multidimensional practices that will constitute the draft of Ukrainian philosophers' collective monograph.

\section{[D] References}

Bogataya, Lidiya. On the Way to Multidimensional Thinking. Odessa: Pechatnyiy dom, 2010. Dzykovych, Olga, and Sandra J. Langer. Announcement-annotation texts: definition, correlation and synthesis. Advanced Education, 7, 2017: 28-32.

Collins, Randall. The Sociology of Philosophies: A Global Theory of Intellectual Change. Novosibirsk: Sibirskiy hronograf, 2002.

Krzhizhanovsky, Sisigmund. Poetics of the Titles. Moscow: Nikitin Subbotniks, 1931.

Marcel, Gabriel. The Fifth Lecture (From a series of the Gifford Lectures). Primary and secondary reflections. Existentialist orientation. History of Philosophy, Volume 10, 2003: 144-163.

Moretti, Franco. Dismant Reading. Moscow: Izdatelstvo Instituta Gaydara, 2016.

Soloviev, Vladimir. The Philosophical Principles of Integral Knowledge. Moscow: Myisl, Volume 2, 1990. 